\title{
Economia de Energia no Sistema de Abastecimento de Água: Uma Abordagem Usando Algoritmos Genéticos
}

\author{
Emanuel da Costa Luz
}

Angelita Maria De Ré

Fábio Hernandes

1,2,3 Departamento de Ciência da Computação, Universidade Estadual do Centro-Oeste, Guarapuava, PR.

\section{Maria José de Paula Castanho ${ }^{4}$}

Departamento de Matemática, Universidade Estadual do Centro-Oeste, Guarapuava, PR.

\begin{abstract}
Resumo. Este trabalho apresenta um algoritmo genético visando melhorar a operação de uma estação de tratamento de água. O objetivo é determinar o tempo de funcionamento das bombas, diminuindo os custos de energia do bombeamento de água e satisfazendo as restrições operacionais do sistema. Os resultados apontaram economia de aproximadamente $18 \%$.
\end{abstract}

Palavras-chave. Abastecimento de água, Energia Elétrica, Algoritmos genéticos.

\section{Introdução}

Nas últimas décadas, vários especialistas têm estudado sobre fontes alternativas para gerar energia e suprir a demanda global. Existem diversas fontes consumidoras de energia, sendo as Estações de Tratamento de Água (ETA) uma das principais, pois, consomem cerca de três por cento da energia nacional com o abastecimento de água e tratamento de esgotos e, desse total, mais de $90 \%$ destina-se ao uso de motores e bombas [6]. O alto consumo de energia das ETA deve-se, muitas vezes, aos equipamentos, que são obsoletos e não são dimensionados conforme a necessidade, o que faz com que operem durante os horários de pico (mais caros). Aliado à precariedade dos motores também estão as grandes perdas de água nas redes de distribuição.

Economizar energia nas ETA é possível desde que se invista em equipamentos sofisticados ou se defina regras de operações, sendo esta segunda opção a mais viável economicamente. Com isso, alguns autores tem abordado o tema, dentre os quais se destacam Firmino et al. [5], Albuquerque [1], Cunha [3], Costa et al. [2], Outeiro et al. [6,7] e Dutra e Alfatini [4], cujos trabalhos referem-se às estações de água das cidades

\footnotetext{
1 emanuel.luz@bol.com.br

2 angelita@unicentro.br

3 hernandes@unicentro.br

${ }^{4}$ zeza@unicentro.br
} 
de Campina Grande - PB [1, 5], São Carlos - SP, Ourém-Portugal, Guarapuava - PR e Caxias do Sul - RS, respectivamente. O trabalho de Firmino et al. [5], aplicado ao problema de acionamento dos conjuntos motor-bomba do principal sistema de abastecimento de água da cidade de Campina Grande-PB, foi dividido em duas etapas, na primeira a aplicação de programação linear e na segunda o uso da programação linear inteira, apresentando resultados que mostraram uma economia financeira de $15,09 \%$ e de consumo energético de 16,86\%. No trabalho de Albuquerque [1], também aplicado ao problema de Campina Grande - PB, foram utilizados os métodos de otimização, Programação Linear (PL) e Não Linear (PNL), além de Algoritmos Genéticos (AG), obtendo como resultados uma economia financeira de $20,27 \%$ e de consumo energético de $16,86 \%$. O trabalho de Cunha [3] apresenta um modelo computacional, utilizando algoritmos genéticos e o software Epanet ${ }^{5}$, para otimização energética de um sistema de abastecimento da cidade de São Carlos - SP, obtendo resultados que demonstram a eficiência do modelo em encontrar soluções factíveis de serem implementadas e com redução de custo de energia elétrica na ordem de 8,5\%. Costa et al. [2] apresentaram um algoritmo genético híbrido em conjunto com o Epanet para determinar as estratégias de operações com custos energéticos reduzidos no sistema de abastecimento de água de Ourém-Portugal. Outeiro et al. [6] abordaram o problema de economia de energia com o bombeamento de água por meio da programação linear fuzzy e do software Matlab, aplicando-o ao sistema de tratamento de água da cidade de Guarapuava-PR. O problema foi modelado levando em consideração o mês de janeiro de 2013, reduzindo os gastos em torno de $20 \%$, pois o sistema trabalhou com pouca intensidade no horário de ponta (horário em que a energia é mais cara). Dutra e Alfatini [4] abordaram o problema de distribuição de água e consumo de energia do sistema de bombeamento Santa Fé da cidade de Caxias do Sul. Os autores utilizaram planilhas eletrônicas e o software Epanet para verificar que com a troca de três bombas e o uso do inversor de frequência para controlar a velocidade de rotação deste sistema a economia mensal estimada de energia seria em torno de $37 \%$.

Como se verifica, os trabalhos supracitados utilizaram métodos clássicos de otimização (Programação Linear, Inteira, Não-Linear), algoritmos genéticos e o Epanet e obtiveram resultados significativos. Logo, este trabalho tem por objetivo aplicar algoritmos genéticos no problema de redução dos custos de energia com bombeamento de água, durante o período de 24 horas, sob determinado esquema tarifário da concessionária de energia elétrica do sistema de captação de água da cidade de Guarapuava-PR.

Este trabalho está organizado da seguinte forma: na Seção 2 estão os materiais e métodos, na Seção 3 são apresentados os resultados computacionais e na Seção 4 as conclusões.

${ }^{5}$ Epanet - simulador para execução estática e dinâmica do comportamento hidráulico e de qualidade de água de sistemas de distribuição de água (http: Ilwww.epa.gov.Inrmllwswrdlepanet)

\section{Materiais e Métodos}

A companhia responsável pelo abastecimento e tratamento de água no município de Guarapuava, PR, é a Companhia de Saneamento do Paraná, localizada no bairro 
Santana. A captação de água é feita no Rio das Pedras de onde partem duas adutoras, ${ }^{3}$ uma de $400 \mathrm{~mm}$ e outra de $350 \mathrm{~mm}$, com comprimento de $1112 \mathrm{~m}$ e uma elevação de aproximadamente $100 \mathrm{~m}$. A estação de captação possui três motores, com a restrição de que até dois podem funcionar ao mesmo tempo, para que a vazão não seja maior que a capacidade de tratamento, sendo dois de $600 \mathrm{cv}$ e um de $450 \mathrm{cv}$, com vazão de $600 \mathrm{~m}^{3} / \mathrm{h}$, $432 \mathrm{~m}^{3} / \mathrm{h}$, respectivamente. A capacidade de tratamento da ETA em operação é de 3301/s. A estação possui quatro reservatórios, que estão interligados, somando uma capacidade máxima de $9200 \mathrm{~m}^{3}$. Para evitar cavitação o volume mínimo adotado é de $3066 \mathrm{~m}^{3}$.

Um esquema simplificado do sistema é apresentado na Figura 1.

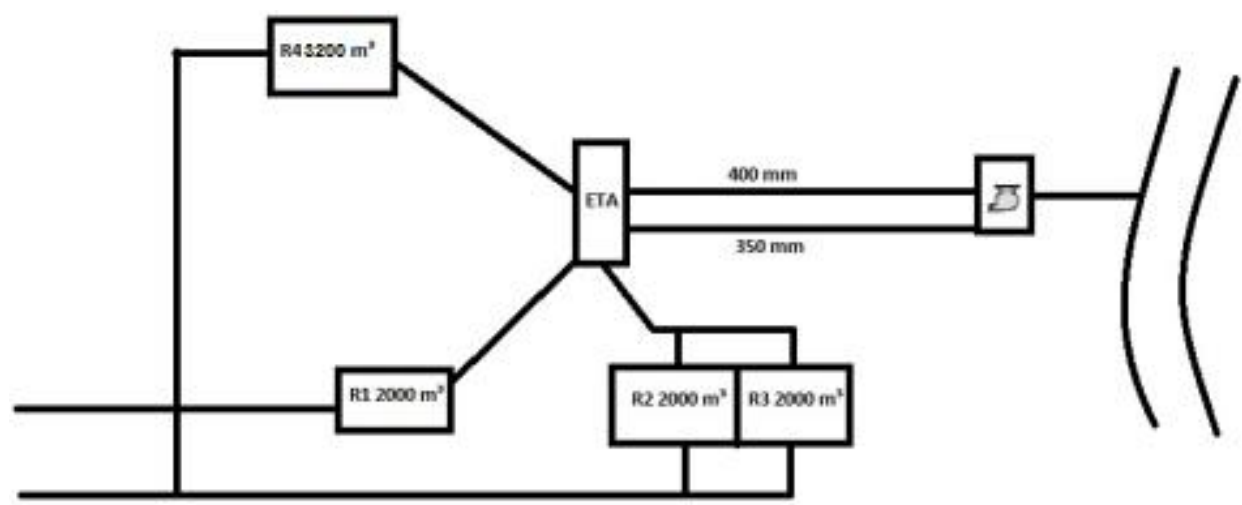

Figura 1: Esquema da ETA em Guarapuava - PR [7].

A empresa responsável pelo fornecimento de energia é a ENERGISA. A tarifa adotada é a horo-sazonal verde, na qual se pactua a demanda contratada no horário de ponta e fora de ponta com tarifas diferenciadas de $\mathrm{R} \$ 0,59 /$ hora e $\mathrm{R} \$ 0,14 /$ hora, respectivamente. $\mathrm{O}$ horário de ponta ocorre das 18 horas às 21 horas.

Atualmente, não há um padrão estabelecido para o processo de operação das bombas. Um operador técnico experiente, observando os níveis dos reservatórios e sabendo os horários de maior demanda, executa a ação de ligar/desligar os motores.

Tendo em vista que o objetivo deste trabalho é reduzir os custos com energia do sistema de bombeamento de água descrito anteriormente, na Seção 2.1 é apresentada a função objetivo e as restrições do problema, enquanto que na Seção 2.2 está a descrição do algoritmo genético implementado.

\subsection{Formulação do problema}

Considerando que os custos da energia elétrica em sistemas de distribuição de água representam a maior parte dos custos totais relativos às despesas operacionais, a função objetivo, definida para 24 horas de funcionamento dos motores, tendo como base a tarifa horária de operação, é dada por:

$$
Z=\sum_{t=1}^{24}\left[441 * T(t) * X_{1}(t)+331 * T(t) * X_{2}(t)+441^{*} T(t) * X_{3}(t)\right]
$$

tal que: $Z$ é o custo diário de energia que o sistema de abastecimento gasta com o bombeamento; 441 e 331 representam o consumo em $\mathrm{KW} / \mathrm{h}$ de cada motor, $T(t)$ é a tarifa de consumo em $(\mathrm{R} \$ / \mathrm{KWh})$ no período de análise $t$ e $X_{i}, i=1,2,3$, é o tempo $t \mathrm{em}$ que o motor necessita estar ligado.

A relação entre a captação de água, a capacidade de tratamento da ETA e os 
níveis dos reservatórios para atendimento das demandas diárias, deve ser observada no procedimento de otimização da operação do sistema. Dessa forma, podem ser consideradas as seguintes restrições:

- as vazões horárias nas adutoras são caracterizadas pelo funcionamento em paralelo dos motores. Cada motor deverá funcionar uma fração de tempo a cada hora: $0 \leq X_{i}(t) \leq 60$;

- a capacidade máxima dos reservatórios deve ser considerada, além do volume mínimo para evitar cavitação. Assim: $3066 \leq V(t) \leq 9200$;

- a vazão de água bombeada pela ETA, a cada hora, deve ser menor ou igual à capacidade de tratamento: $594 * X_{1}(t)+432 * X_{2}(t)+594 * X_{3}(t) \leq 1188$;

- deverá haver confiabilidade no atendimento de demandas que variam a cada hora, sendo: $D_{\max }=1844 \mathrm{~m}^{3}$ e $D_{\min }=368 \mathrm{~m}^{3}$.

\subsection{Algoritmo genético proposto}

Para a implementação do Algoritmo Genético foram definidas duas restrições: a primeira diz respeito à demanda de produção dos motores, que deverá permanecer sempre igual ou inferior a $1188 \mathrm{~m}^{3}$, e a segunda com relação à capacidade dos reservatórios, que deverá permanecer entre $3066 \mathrm{~m}^{3}$ a $9200 \mathrm{~m}^{3}$.

O indivíduo é composto por conjuntos de genes de tamanho igual a 24 , que representam as horas do dia, onde cada gene possui alelos com três características (representando o conjunto dos três motores), conforme Figura 2.

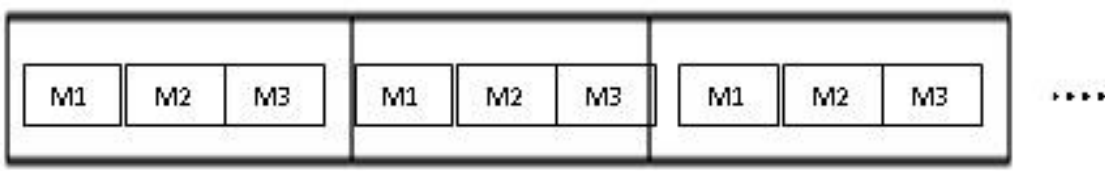

Figura 2: Cromossomo representando o indivíduo.

Inicialmente é gerada aleatoriamente uma população e somente os indivíduos válidos, isto é, que satisfazem as restrições do problema, permanecem nesta, compondo assim uma lista ordenada pelo fitness. Com relação à seleção, são escolhidos indivíduos desta lista que passam para o processo de aplicação dos operadores. Quanto aos operadores, utilizou-se cruzamento e mutação da seguinte forma: (i) o cruzamento recebe dois indivíduos como parâmetro e realiza a operação considerando um ponto de corte, podendo ser fixo ou aleatório. Na sequência, após realizar o cruzamento, é verificado se o novo indivíduo satisfaz as restrições do problema. Caso satisfaça, retornam os filhos válidos, senão retornam os pais; (ii) a mutação seleciona um indivíduo que não consta do intervalo [18-20], que representam os horários de ponta, como parâmetro e realiza a operação permutando aleatoriamente as posições de dois genes. É importante destacar que para a próxima geração busca-se a melhora da população.

Um esquema do algoritmo genético utilizado é apresentado na Figura 3. 


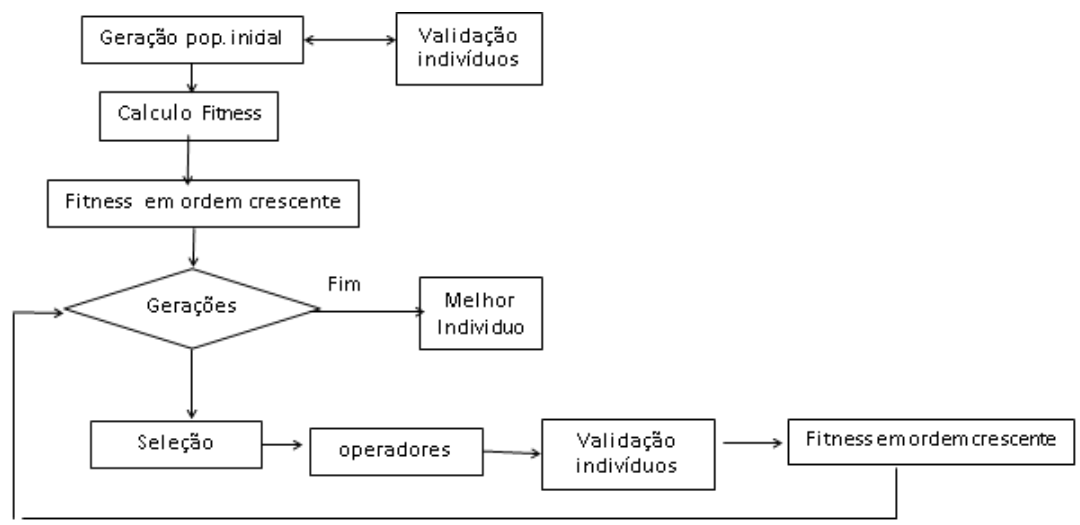

Figura 3: Esquema do algoritmo genético implementado.

\section{Resultados Computacionais}

Considerando que o objetivo do problema é minimizar os gastos com energia elétrica no processo de bombeamento de água da ETA, o fitness do algoritmo genético implementado é a função objetivo do problema, descrita na Seção 2.1.

Devido à capacidade de tratamento da ETA, somente dois motores podem funcionar concomitantemente, ou seja, em cada gene do cromossomo (Figura 2) pelo menos uma característica deve ser nula, isto é, a cada hora a soma do funcionamento dos motores não pode ultrapassar a 120 minutos.

Os dados utilizados neste trabalho foram adquiridos junto à Companhia de Saneamento do Paraná da cidade de Guarapuava e se referem ao mês de janeiro.

Independente do dia da semana, durante as vinte e quatro horas, verifica-se que os horários de maior consumo de água estão entre 11 às $15 \mathrm{~h}$ e 18 às $20 \mathrm{~h}$. Logo, para as restrições do problema que tratam do volume dos reservatórios foi considerada a média horária do dia.

No total foi executada uma bateria de testes com a população inicial variando de 50 em 50 indivíduos até 200. O número de gerações testado foi 50, 100, 200 e 1000. Devido ao fato de que a mutação utilizada realiza permuta entre os genes, não alterando o seu conteúdo, o mesmo tende a não alterar o fitness; assim optou-se por uma taxa alta de mutação, variando entre 0,3 e 0,5. Em testes anteriores, observou-se que uma taxa baixa de cruzamento não contribuía na melhora das soluções, assim, decidiu-se pelas taxas entre 0,6 e 0,9 .

Dentre os vários testes, a Tabela 1 apresenta as configurações das seis melhores médias de fitness.

Tabela 1: Melhores resultados.

\begin{tabular}{|c|c|c|c|c|}
\hline Gerações & $\begin{array}{c}\text { Taxa - } \\
\text { Cruzamento }\end{array}$ & $\begin{array}{c}\text { Taxa }- \\
\text { Mutação }\end{array}$ & $\begin{array}{c}\text { Ponto de } \\
\text { corte }\end{array}$ & Fitness \\
\hline 100 & 0,6 & 0,5 & Aleatório & 2531,2 \\
\hline 100 & 0,7 & 0,5 & Fixo & 2637,67 \\
\hline 100 & 0,6 & 0,3 & Aleatório & 2647,84 \\
\hline 200 & 0,6 & 0,3 & Aleatório & 2676,25 \\
\hline 200 & 0,7 & 0,5 & Fixo & 2680,59 \\
\hline 200 & 0,6 & 0,5 & Aleatório & 2691,21 \\
\hline
\end{tabular}


Com os resultados obtidos, a combinação das taxas 0,6 e 0,5 de cruzamento e mutação, respectivamente, foi a que apresentou o melhor fitness $(2531,2)$, o que representou uma economia média de aproximadamente $18 \%$, quando comparado com o gasto médio mensal informado pela companhia.

A Figura 3 mostra o melhor indivíduo, composto pelo tempo de funcionamento dos três motores, durante as 24 horas. É possível perceber que no horário de ponta, onde a energia é mais cara, funciona apenas um motor de $600 \mathrm{CV}$ num total de 39 minutos.

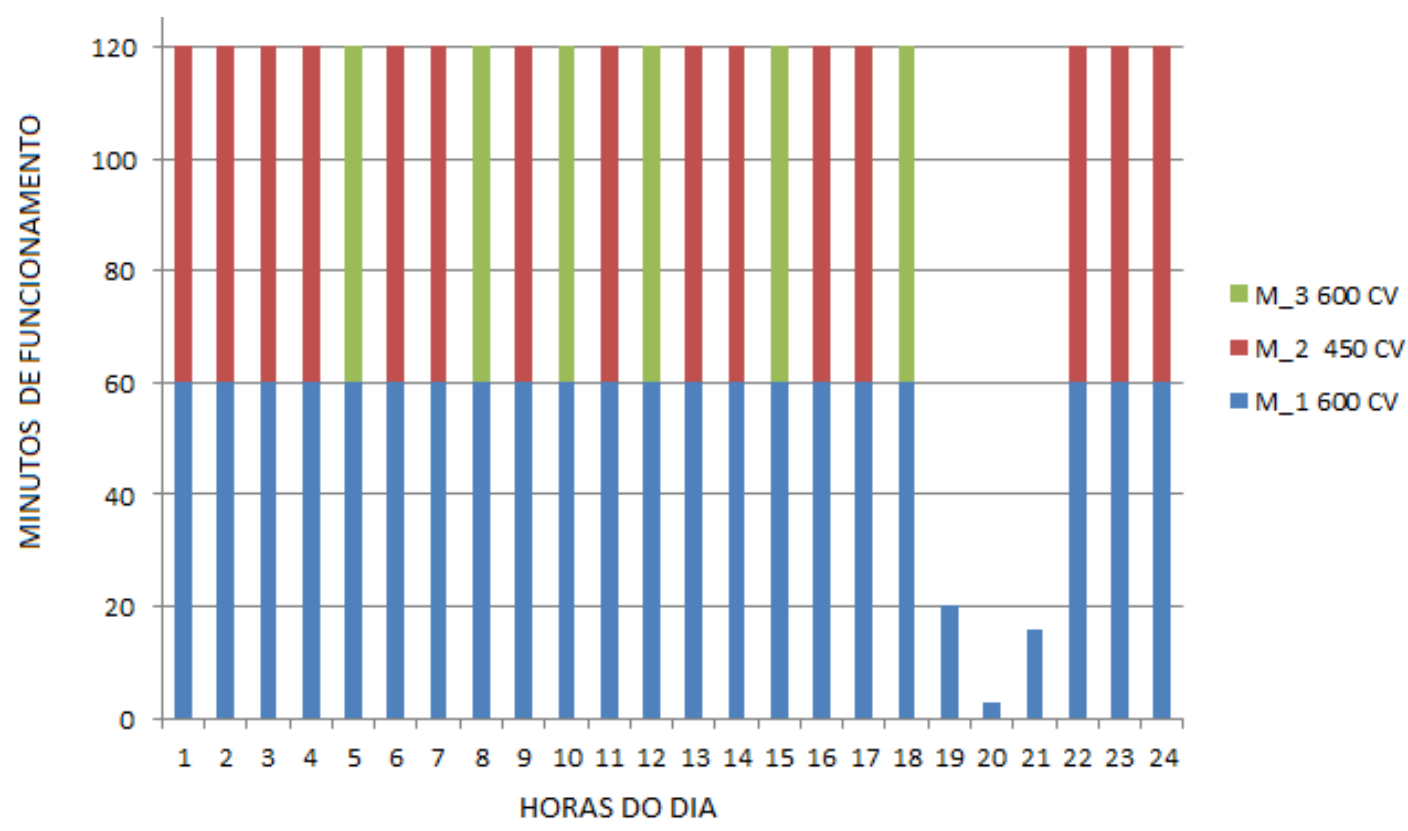

Figura 3. Tempo de funcionamento dos três motores ao longo das 24 horas

\section{Discussões e Conclusões}

A grande demanda energética brasileira revela a importância e urgência de se buscar soluções alternativas, nos sistemas de saneamento, que venham a diminuir o impacto ambiental, bem como reduzir os custos elevados com energia na área. Nas últimas décadas, estudos demonstram que mais de $2 \%$ do consumo total de energia elétrica do Brasil, equivalente a 8,3bilhões de Kwh/ano, são consumidos por prestadores de serviços de saneamento em todo o país. Este consumo engloba os diversos usos nos processos de abastecimento de água e esgotamento sanitário, com destaque para os conjuntos motobomba, que são normalmente responsáveis por $90 \%$ do consumo nestas instalações [8].

Neste trabalho foi proposto um algoritmo genético cujo objetivo era reduzir os custos de energia elétrica no processo de bombeamento de água da cidade de Guarapuava-PR pela Companhia de Saneamento do Paraná. Não é possível estabelecer uma comparação dos resultados obtidos a partir do modelo proposto com a prática atual da companhia, pois esta não apresenta um padrão diário. Entretanto, os resultados mostraram que a redução do uso dos motores nos horários de ponta (horários mais caros) faz com que os custos diminuam em até $18 \%$, o que também é comprovado por Tsutiya [9] que destaca "a parada das bombas no horário de ponta tem sido realizada com sucesso, tanto em pequenos sistemas de abastecimento de água quanto em grandes sistemas, como é o caso da região metropolitana 
de São Paulo. De um modo geral essa alteração operacional tem representado cerca de $10 \mathrm{a}^{7}$ $20 \%$ na redução dos custos de energia elétrica".

Como trabalhos futuros pretende-se ampliar o período de coleta de dados para, pelo menos, um ano, aplicando em outros modelos de operadores genéticos, além de outras técnicas.

\section{Referências}

[1] A. A. Albuquerque, Análise e métodos de otimização para eficiência energética de estações elevatórias em sistemas de abastecimentos de água, Tese de Doutorado em Recursos Naturais, Universidade Federal de Campina Grande, (2007).

[2] L. H. M. Costa, M. A. H. Castro e H. Ramos, Utilização de um algoritmo genético híbrido para operação ótima de sistemas de abastecimento de água, Engenharia Sanitária e Ambiental, vol. 15, número 2, 187-196, (2010).

[3] A. P. A. R. Cunha, Otimização energética em tempo real da operação de sistemas de abastecimento de água, Dissertação de Mestrado na Escola de Engenharia da Universidade de São Paulo - São Carlos - SP, (2008).

[4] R. F. Dutra e C. R. Altafini, Melhorias em um sistema de bombeamento municipal visando à Eficiência Energética - Estudo de Caso, Scientia Cum Industria (Sci. Cum Ind.), vol. 2, 1 - 9, (2014).

[5] M. B. Firmino, A, A. Albuquerque, W. F. Curi e N. C. Silva, Método de eficiência energética no bombeamento de água, via programação linear e inteira. Anais do VI Seminário Iberoamericano sobre Sistemas de Abastecimento Urbano de Água SEREA, João Pessoa - PB, vol.1 (2006).

[6] V. H. Outeiro, M. J. P. Castanho e F. Hernandes, Racionalização de energia com o bombeamento de água. Anais do Congresso de Matemática Aplicada e Computacional, CMAC Sudeste, p. 169-171 (2013).

[7] V. H. Outeiro, M. J. P. Castanho e F. Hernandes, Uso de Programação Matemática Fuzzy para Reduzir Custos de Energia. Anais do XXXV Congresso Nacional de Matemática Aplicada e Computacional - CNMAC, Natal - RN (2014).

[8] PROCEL SANEAR, Plano de ação Procel Sanear 2006/2007, Eletrobrás, (2005).

[9] M. T. Tsutiya, Redução do custo de energia elétrica em sistemas de abastecimento de água, ABES - Associação Brasileira de Engenharia Sanitária e Ambiental, ABES Seção São Paulo, São Paulo, $1^{a}$ Edição, (2001). 